\title{
Early Transition Metal Doped Tungstite as an Effective Catalyst for Glucose Upgrading to 5-Hydroxymethylfurfural
}

\author{
Jan J. Wiesfeld ${ }^{1}$. Nico A. J. M. Sommerdijk ${ }^{2}$ Emiel J. M. Hensen ${ }^{1}$
}

Received: 9 June 2018 / Accepted: 4 July 2018 / Published online: 10 August 2018

(c) The Author(s) 2018

\section{Abstract}

Glucose valorization to 5-hydroxymethylfurfural (HMF) remains challenging in the transition towards renewable chemistry. Lewis acidic tungstite is a viable, moderately active catalyst for glucose dehydration to HMF. Literature reports a multistep mechanism involving Lewis acid catalyzed isomerization to fructose, which is then dehydrated to HMF by Brønsted acid sites. Doping tungstite with titanium and niobium improves activity by optimizing the ratio between Lewis and Brønsted acid sites.

\section{Graphical Abstract}

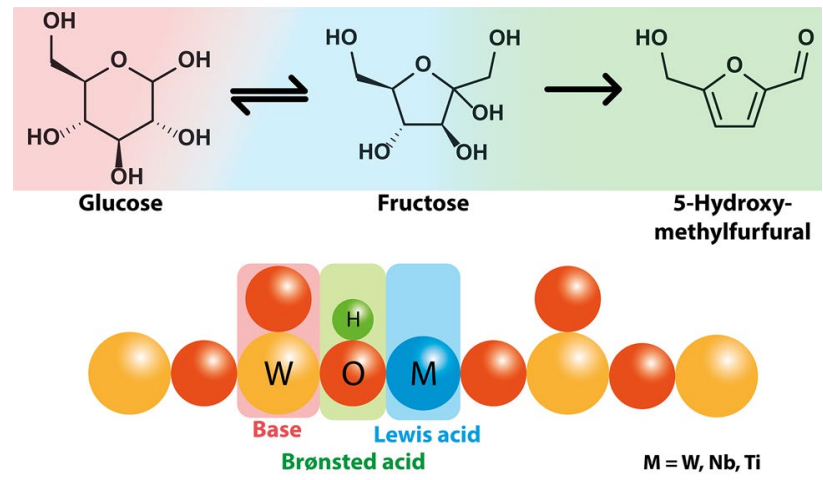

Keywords Biomass $\cdot$ Glucose $\cdot 5$-Hydroxymethylfurfural $\cdot$ Tungsten oxide $\cdot$ Doping

Emiel J. M. Hensen

e.j.m.hensen@tue.nl

Jan J. Wiesfeld

j.j.wiesfeld@tue.nl

Nico A. J. M. Sommerdijk

n.a.j.m.sommerdijk@tue.nl

1 Laboratory of Inorganic Materials Chemistry, Schuit Institute of Catalysis, Eindhoven University of Technology, P.O. Box 513, 5600 MB Eindhoven, The Netherlands

2 Laboratory of Materials and Interface Chemistry, Eindhoven University of Technology, P.O. Box 513, 5600 MB Eindhoven, The Netherlands

\section{Introduction}

Continuous consumption of ever-diminishing fossil resources and the negative impact on the environment associated with their combustion calls for their replacement with alternative renewable feedstocks. Lignocellulosic biomass is a promising starting material for the production of sustainable fuels and chemicals [1,2]. Upgrading of biomass will likely revolve around a select number of platform molecules with a wide variety of downstream applications [3, 4]. 5-Hydroxymethylfurfural (HMF) is regarded as one of the most versatile platform chemicals, its derivatives having potential applications as fuel additives, solvents and monomers for the plastics industry $[5,6]$.

HMF can essentially be obtained from both fructose and glucose. While fructose is easier to upgrade to HMF, it is 
also costly and scarce compared to glucose [7-9]. Glucose can be obtained from lignocellulosic biomass in relatively pure form, making it cheap and abundant compared to fructose. These aspects make glucose an attractive feedstock for HMF [10-13]. However, the upgrading of glucose to HMF is much more challenging than that of fructose [14-16]. While mineral acids such as $\mathrm{HCl}$ and $\mathrm{H}_{2} \mathrm{SO}_{4}$ can be used as catalysts for the conversion of either sugar to HMF in aqueous solution at elevated temperatures, especially glucose suffers from severe degradation to humins under these conditions [17-19]. Also, HMF can be rehydrated to levulinic acid in water of low $\mathrm{pH}[15,18]$. Sustainable HMF production from glucose thus requires specialized and atom-efficient catalysts, as simple Brønsted acids alone are ill-equipped for this purpose.

More efficient routes for glucose to HMF conversion employ a bifunctional system to isomerize glucose to the more reactive fructose prior to its dehydration. Enzymes can facilitate the isomerization, but are incompatible with the acidic conditions necessary for the dehydration. Basic and Lewis acid catalysts can also carry out the isomerization, but Lewis acids are preferred for their stability in acidic environments [20]. While such two-step approaches are viable, one-pot strategies have attracted much interest recently. Mechanistically, it is commonly assumed that the conversion of glucose proceeds via fructose as an intermediate. Lewis acids play an important role in isomerizing glucose to the more reactive fructose by stabilizing glucose in its acyclic form, facilitating a 1,2-hydride transfer and releasing fructofuranose (fructose) [21-24]. Subsequent dehydration then removes three water molecules to form HMF (Scheme 1). To optimize the selectivity, the reaction can be carried out in a biphasic or non-aqueous system, thereby shielding HMF from the acidic aqueous environment and preventing rehydration to levulinic acid $[8,16,25]$.

Zeolites have been shown capable of isomerizing glucose to fructose, but require addition of a Brønsted acid to dehydrate the fructose to HMF [14]. Additionally, the synthesis of the most effective zeolite for this purpose, Sn-modified Beta, is cumbersome and requires toxic reagents such as HF [20, 26]. Additionally, zeolites are prone to framework damage when exposed to the high temperatures and aqueous media the reaction requires to proceed, diminishing its activity during prolonged reactions $[27,28]$. Homogeneous catalysts including Lewis acidic metal chlorides in ionic liquids are also unattractive because of the difficulties associated with separation $[29,30]$.

A different branch of catalysts capable of these transformations are transition metal oxides such as $\mathrm{TiO}_{2}, \mathrm{Nb}_{2} \mathrm{O}_{5}$ and $\mathrm{WO}_{3}$. These materials are abundant and cheap, and express water-tolerant Lewis acid sites and tunable acid-base properties with promising glucose-upgrading abilities [31, 32]. Recently, we have shown that tungstite $\left(\mathrm{WO}_{3} \cdot \mathrm{H}_{2} \mathrm{O}\right)$ is also a viable contender [33]. The material comprises distorted $\mathrm{WO}_{5} \cdot \mathrm{H}_{2} \mathrm{O}$ octahedra, which share 4 equatorial corner oxygens to form a stacked sheet-like material with a low surface area. Perpendicular to each sheet, every W site is terminated alternatingly by a double bonded oxygen and coordinated water. Similarly to $\mathrm{TiO}_{2}$ and $\mathrm{Nb}_{2} \mathrm{O}_{5}$, it contains water-tolerant Lewis acid functionalities, but its Brønsted acidity is relatively weak, which limits fructose dehydration rates. Doping the material with $\mathrm{Nb}$ proved a key factor in enhancing its activity [33].

In this work, we explored the effect of titanium as a dopant on the activity of tungstite, based on the results found by DFT calculations [34]. The materials were characterized in detail with the aim to judge the dispersion of the dopant in the bulk and at the surface of tungstite.

\section{Experimental Methods}

\subsection{Chemicals}

Tungsten hexachloride $\left(\mathrm{WCl}_{6}, 99 \%\right.$, Alfa Aesar), niobium pentachloride $\left(\mathrm{NbCl}_{5}, 99.9 \%\right.$, Alfa Aesar), titanium tetrachloride $\left(\mathrm{TiCl}_{4}, 99 \%\right.$, Sigma Aldrich) were kept in an MBraun glovebox under an inert argon atmosphere.

Titanium(IV) oxide ( $\mathrm{TiO}_{2}$, Degussa P25) and niobium(V) oxide $\left(\mathrm{Nb}_{2} \mathrm{O}_{5}, 99.5 \%\right.$ Alfa Aesar) were used as commercial standards.

D-(-)-glucose (99\%, Sigma Aldrich), 5-hydroxymethylfurfural (HMF, 97\%, Sigma Aldrich), tetrahydrofuran (THF, 99\%, Biosolve), triethylamine (TEA, 99.9\%, VWR) and acetonitrile (MeCN, HPLC-S grade, Biosolve) were used as received. Pyridine (Sigma Aldrich, 99\%) was stored on freshly activated $3 \AA$ molsieves (Merck).

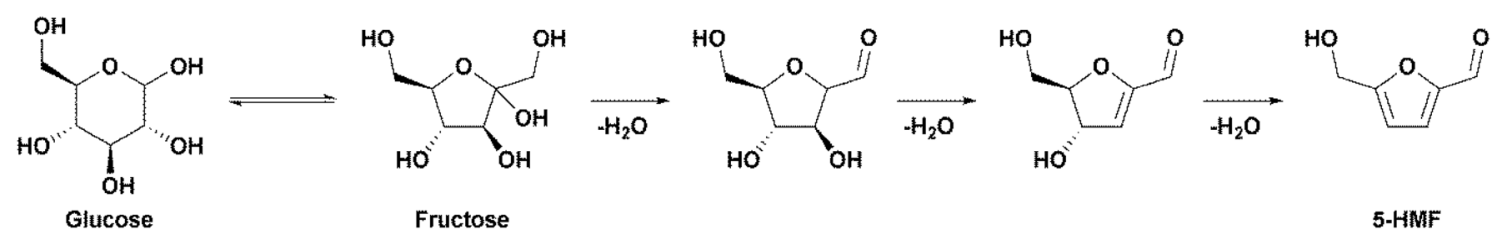

Scheme 1 Reaction intermediates in the conversion of glucose to HMF 
Deionized water (15 and 18.2 M $\Omega$ ) was obtained from an Elgastat Water Purifier present in our laboratory.

\subsection{Catalyst Preparation}

Preparation of $\mathrm{WO}_{3}: \mathrm{WCl}_{6}(3.97 \mathrm{~g} ; 10.0 \mathrm{mmol})$ was dispersed in $160 \mathrm{~mL}$ deionized water in an open beaker in contact with air to initiate hydrolysis. The suspension was kept at $50{ }^{\circ} \mathrm{C}$ overnight while stirred magnetically. The yellow precipitate was collected by filtration and washed several times with deionized water until neutral $\mathrm{pH}$ of the filtrate was reached. The residue was then dried at $60{ }^{\circ} \mathrm{C}$ in vacuo overnight. $\mathrm{NbWx}$ (x representing $\mathrm{W} / \mathrm{Nb}$ ratios of 10 and 5) samples were prepared in a similar fashion using physical mixtures of appropriate amounts of $\mathrm{WCl}_{6}$ and $\mathrm{NbCl}_{5}$. TiWx (W/Ti ratios of 10 and 5) were prepared by adding an appropriate amount of $\mathrm{WCl}_{6}$ to $160 \mathrm{~mL}$ water first and injecting the correct amount of $\mathrm{TiCl}_{4}$ within $10 \mathrm{~s}$ using a Finn pipette with the tip submerged in the water. After drying, the materials were used without further treatment.

\subsection{Characterization}

Elemental analysis was performed on a Spectroblue EOP ICP optical emission spectrometer with axial plasma viewing, equipped with a free-running 27.12 $\mathrm{MHz}$ generator operating at $1400 \mathrm{~W}$. Prior to the measurement, the samples were digested using a $4 \mathrm{M} \mathrm{KOH}$ solution. For Ti containing materials an equal volume of $8 \mathrm{vol} \% \mathrm{HF}$ was added to dissolve the titanium under gentle heating $\left(\sim 40{ }^{\circ} \mathrm{C}\right)$.

$X$-ray photoelectron spectroscopy (XPS) was performed on a Thermo Scientific K-alpha equipped with a monochromatic small-spot X-ray source and a $180^{\circ}$ double focusing hemispherical analyzer with a 128 -channel detector. Initial pressure was $8 \times 10^{-8}$ mbar or less which increased to $2 \times 10^{-7}$ mbar due to the active argon charge compensation dual beam source during measurement.

For a typical sample preparation, fresh catalyst was pressed down on carbon tape supported by an aluminium sample plate. Spectra were recorded using an $\mathrm{Al}_{\mathrm{K} \alpha} \mathrm{X}$-ray source $(1486.6 \mathrm{eV}, 72 \mathrm{~W})$ and a spot size of $400 \mu \mathrm{m}$. Survey scans were taken at a constant pass energy of $200,0.5 \mathrm{eV}$ step size, region scans at $50 \mathrm{eV}$ constant pass energy with a step size of $0.1 \mathrm{eV}$.

XPS spectra were calibrated to the $\mathrm{C}-\mathrm{C}$ carbon signal $(284.8 \mathrm{eV})$ obtained from adventitious carbon and deconvoluted with CasaXPS. The peak areas thus obtained were used to estimate surface chemical composition.

Nitrogen sorption data was recorded on a Micrometrics Tristar 3000 in static measurement mode at $-196^{\circ} \mathrm{C}$. The samples (typically $150 \mathrm{mg}$ ) were pretreated at $120^{\circ} \mathrm{C}$ under a gentle $\mathrm{N}_{2}$ stream overnight prior to the sorption measurements. The Brunauer-Emmett-Teller (BET) equation was used to calculate the specific surface area $\left(\mathrm{S}_{\mathrm{BET}}\right)$ from the adsorption data $\left(\mathrm{p} / \mathrm{p}^{0}=0.05-0.25\right)$.

Transmission electron microscopy (TEM) images were obtained in bright field mode from a FEI Tecnai 20 (type Sphera) operating with $\mathrm{LaB}_{6}$ filament at $200 \mathrm{kV}$ and a bottom mounted $1024 \times 1024$ Gatan msc 794 TM CCD camera and elemental mapping was performed on a probe $\mathrm{Cs}$ corrected $\operatorname{Titan}^{2}$ (FEI) operating at $300 \mathrm{kV}$ in ADF-STEM mode using an Oxford Instruments X-Max ${ }^{\mathrm{N}}$ 100TLE EDX detector. Suitable samples were prepared by dropping a suspension of finely ground material in analytical grade absolute ethanol onto Quantifoil R 1.2/1.3 holey carbon films supported on a copper grid.

Powder X-ray diffraction (XRD) patterns were recorded on a Bruker Endeavour D2 Phaser diffractometer using $\mathrm{Cu}$ $\mathrm{K} \alpha$ radiation with a scanning speed of $0.6^{\circ} \mathrm{min}^{-1}$ in the range of $5^{\circ} \leq 2 \theta \leq 60^{\circ}$. Crystal phases were identified using the DIFFRAC.EVA software package and the PDF-2 crystallographic database (version 2008).

Fourier-transformed infrared (FT-IR) was used to evaluate acidic properties of the materials. Spectra were recorded in the range of $4000-1200 \mathrm{~cm}^{-1}$ at a resolution of $2 \mathrm{~cm}^{-1}$ on a Bruker Vertex V70v equipped with a DTGS detector and $\mathrm{CaF}_{2}$ windows. A total of 64 scans were averaged for each spectrum. Typically, finely powdered material was pressed into self-supporting wafers with density $\rho \simeq 25 \mathrm{mg} \mathrm{cm}^{-2}$ using a pressing force of $3000 \mathrm{~kg}$, and placed inside a variable temperature IR transmission cell coupled to a closed gas circulation system. The samples were then outgassed at $70{ }^{\circ} \mathrm{C}$ in vacuo until a pressure of $2 \times 10^{-5}$ mbar or lower was reached.

Prior to pyridine adsorption, the sample was kept at $70{ }^{\circ} \mathrm{C}$ and a sample background was recorded. Pyridine was then introduced into the cell until saturation was reached, and physisorbed pyridine was removed in vacuo for $1 \mathrm{~h}$. A second spectrum were recorded in situ at this point.

Difference spectra were obtained by subtraction of the sample background from the recorded spectra. Processing and deconvolution of the signals was performed with Fityk curve fitting program.

\subsection{Catalytic Activity Tests}

Batch reactions were performed at $120^{\circ} \mathrm{C}$ under autogenous pressure in Pyrex tubes (inner volume $12 \mathrm{~mL}$ ) equipped with a magnetic stirring bar. For a typical experiment, 5 tubes were each charged with $40 \mathrm{mg}$ glucose dissolved in $4 \mathrm{~mL}$ of a biphasic $\mathrm{H}_{2} \mathrm{O} / \mathrm{THF}$ mixture, volume ratio $1 / 9$, in which $40 \mathrm{mg}$ of catalyst was suspended and sealed with a PTFE stopper. After a corresponding reaction time, the reaction was quenched by immersion of the tube in an ice/water bath. Reaction times of 30, 60, 120, 180 and 240 min were used. 
Aliquots were filtered through a $0.45 \mu \mathrm{m}$ PTFE filter and analyte concentrations were determined by a Shimadzu HPLC system equipped with autosampler and column oven. Glucose and fructose were separated on a Shodex Asahipak NH2P-50 2D kept at $35^{\circ} \mathrm{C}$ and detected by ELSD (ELSDLT II operating at $40{ }^{\circ} \mathrm{C}$, gas pressure $350 \mathrm{kPa}$ ) using 70:30 $\mathrm{MeCN}: \mathrm{H}_{2} \mathrm{O}$ modified with $0.001 \mathrm{M}$ TEA as mobile phase $\left(0.2 \mathrm{~mL} \mathrm{~min}^{-1}\right)$. HMF was measured by UV-Vis (SPDM20A operating at $40{ }^{\circ} \mathrm{C}, \lambda_{\max } 284 \mathrm{~nm}$ ) using a Phenomenex Kinetex 5u EVO C18 100A reversed phase column at $40{ }^{\circ} \mathrm{C}$ for separation and 5:95 MeCN: $\mathrm{H}_{2} \mathrm{O}$ as mobile phase $\left(0.4 \mathrm{~mL} \mathrm{~min}^{-1}\right)$.

Conversion, yield and selectivities of the respective compounds were calculated using the following formulas and converted to percentages when appropriate:

$X=\left(1-\frac{n_{t}}{n_{0}}\right) ; Y_{p}=\left(\frac{n_{p}}{n_{0}}\right)$

where $\mathrm{X}$ is the conversion of glucose, $\mathrm{Y}_{\mathrm{P}}$ the product yield, $\mathrm{n}_{0}$ and $\mathrm{n}_{\mathrm{t}}$ the glucose concentrations at $\mathrm{t}=0$ and $\mathrm{t}=$ reaction time, and $\mathrm{n}_{\mathrm{P}}$ the product concentration.

\section{Results and Discussion}

Hydrolysis of $\mathrm{WCl}_{6}$ in water initially yielded a gray suspension, which turned yellow overnight. Collection and drying of the formed material provided a vividly yellow, easy to disperse solid. Hydrolysis of the $\mathrm{NbCl}_{5} / \mathrm{WCl}_{6}$ physical mixtures behaved similarly and yielded similarly yellow colored, more voluminous oxides NbW10 and NbW5 $(\mathrm{W} / \mathrm{Nb}=10$ or 5). On the other hand, the synthesis of TiW10 and TiW5 $(\mathrm{W} / \mathrm{Ti}=10$ or 5$)$ yielded pale-yellowish, very dense, grainy materials.

XPS and ICP results are summarized in Table 1. All doped materials contain the desired amount of dopant as evidenced by ICP. The bulk and surface $\mathrm{W} / \mathrm{Nb}$ ratios of NbW10 and NbW5 match quite well, indicating no surface segregation. However, the content of titanium in the bulk of the TiWx samples is significantly higher than the surface

Table 1 Atomic surface concentrations of $\mathrm{W}^{\mathrm{VI}} / \mathrm{W}^{\mathrm{V}}$ and surface and bulk W/dopant ratios

\begin{tabular}{lllll}
\hline Sample & $\begin{array}{l}\mathrm{W}^{\mathrm{VI}} 4 \mathrm{f}_{7 / 2} \\
\mathrm{eV} / \%\end{array}$ & $\begin{array}{l}\mathrm{W}^{\mathrm{V}} 4 \mathrm{f}_{5 / 2} \\
\mathrm{eV} / \%\end{array}$ & $\begin{array}{l}\mathrm{W} / \text { dopant } \\
-(\mathrm{XPS})\end{array}$ & $\begin{array}{l}\text { W/dopant } \\
-(\mathrm{ICP})\end{array}$ \\
\hline $\mathrm{WO}_{3}$ & $35.9 / 94.4$ & $34.8 / 5.6$ & - & - \\
NbW10 & $35.9 / 93.6$ & $34.8 / 6.9$ & 10.4 & 10.1 \\
NbW5 & $35.9 / 88.8$ & $34.8 / 11.2$ & 5.78 & 4.98 \\
TiW10 & $35.9 / 94.2$ & $34.8 / 5.8$ & 15.3 & 11.9 \\
TiW5 & $35.9 / 93.5$ & $34.8 / 6.5$ & 11.9 & 4.44 \\
\hline
\end{tabular}

content. Deconvolution of the tungsten $4 \mathrm{f}$ region yields

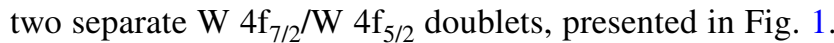
For the $\mathrm{W} 4 \mathrm{f}_{7 / 2}$ peaks, the binding energies were 34.8 and $35.9 \mathrm{eV}$, which could be assigned to $\mathrm{W}^{\mathrm{V}}$ and $\mathrm{W}^{\mathrm{VI}}$ oxidation states, respectively [35]. Deconvolution of the peaks related to the dopants ( $\mathrm{Nb} 3 \mathrm{~d}$ and $\mathrm{Ti} 2 \mathrm{p}$ ) yielded a single doublet for either material. Binding energies for the $\mathrm{Nb} 3 \mathrm{~d}_{5 / 2}$ and $\mathrm{Ti} 2 \mathrm{p}_{3 / 2}$ components were 207.6 and $459.2 \mathrm{eV}$ and were assigned to the fully oxidated states $\left(\mathrm{Nb}^{\mathrm{V}}\right.$ and $\left.\mathrm{Ti}^{\mathrm{IV}}\right)[36,37]$.

Of note is that the amount of $\mathrm{W}^{\mathrm{V}}$ species differs from material to material. The undoped oxide contains $\sim 5.6 \%$ as $\mathrm{W}^{\mathrm{V}}$. Increasing levels of $\mathrm{Nb}$ raise the level of $\mathrm{W}^{\mathrm{V}}$ to $6.9 \%$ for $\mathrm{NbW} 10(\mathrm{~W} / \mathrm{Nb}$ ratio of 10$)$ and to $11 \%$ for NbW5 (W/Nb ratio of 5). Reduction of $\mathrm{W}$ due to the inclusion of niobium has been described before $[38,39]$. Doping $\mathrm{WO}_{3}$ with $\mathrm{Ti}$ also increased the $\mathrm{W}^{\mathrm{V}}$ content, but to a lesser extent. Care was taken to include the $\mathrm{Nb} 4 \mathrm{p}$ and $\mathrm{Ti} 3 \mathrm{p}$ regions, since both overlap with the $\mathrm{W} 4 \mathrm{f}$ region and would present incorrect $\mathrm{W}^{\mathrm{VI}} / \mathrm{W}^{\mathrm{V}}$ ratios if excluded [40]. Finally, no surface chlorine was present on the samples, indicated by the absence of the $\mathrm{Cl} 2 \mathrm{p}$ signal.

Textural properties of the bulk materials were evaluated using $\mathrm{N}_{2}$ physisorption. Surface areas are summarized in Table 2. NbW5 has the highest surface area $\left(35 \mathrm{~m}^{2} \mathrm{~g}^{-1}\right)$ and TiW5 the lowest $\left(5 \mathrm{~m}^{2} \mathrm{~g}^{-1}\right)$. Isotherms of all materials, displayed in Fig. 2, were of the type IV shape with a H3 hysteresis loop, indicative of aggregates of plate-like materials forming slit-like macropores.

TEM micrographs present a sheet-like morphology for $\mathrm{WO}_{3}$, NbW5 and TiW5 (Fig. 3), which is in keeping with the physisorption measurements. The sheets of $\mathrm{WO}_{3}$ and $\mathrm{NbW} 5$ have well-defined edges in contrast to the quite corrugated plane edges of TiW5.

The XRD pattern of $\mathrm{WO}_{3}$ (Fig. 4) shows that it consists primarily of tungstite [PDF 043-0679] with hydrotungstite [PDF 018-1420] as a minor fraction. Both phases consist of stacked planes built up of equatorial corner-sharing $\mathrm{WO}_{5} \cdot \mathrm{H}_{2} \mathrm{O}$ octahedral and each plane is terminated with alternating double bonded oxygen or coordinated $\mathrm{H}_{2} \mathrm{O}$. The planes are held together by hydrogen bonds. The phases primarily differ in an extra layer of water intercalated between every two hydrotungstite planes. Both NbW10 and NbW5 materials comprise a pure hydrotungstite phase, decreasing in crystallinity with increasing $\mathrm{Nb}$ content. TiW10 and TiW5 are mostly amorphous, although a hydrotungstite phase can still be identified in both samples. Probably, this is caused by the tetrahedral coordination that $\mathrm{Ti}^{\mathrm{IV}}$ can adopt, disrupting the otherwise planar tungstite layers [34]. Substituting $\mathrm{W}^{\mathrm{VI}}$ with $\mathrm{Nb}^{\mathrm{V}}$ on the other hand will maintain the planar ordering as $\mathrm{Nb}^{\mathrm{V}}$ can take on a square pyramidal coordination with four equatorially placed oxygens. The planar morphology of all materials affirm the findings found with sorption and TEM measurements. No $\mathrm{Nb}_{2} \mathrm{O}_{5}$ or $\mathrm{TiO}_{2}$ phases were 
Fig. 1 XPS spectra of the asprepared materials. Experimental data are represented by open circles and the fit as a black curve. W $4 \mathrm{f}$ fits are composed of $\mathrm{W}^{\mathrm{VI}}$ (blue) and $\mathrm{W}^{\mathrm{V}}$ (green). $\mathrm{Nb} 4 \mathrm{p}$ and $\mathrm{Ti} 3 \mathrm{p}$ fits overlapping with the $\mathrm{W} 4 \mathrm{f}$ region are indicated in red. Dopant Ti $2 p$ and $\mathrm{Nb} 3 \mathrm{~d}$ fits are displayed in blue

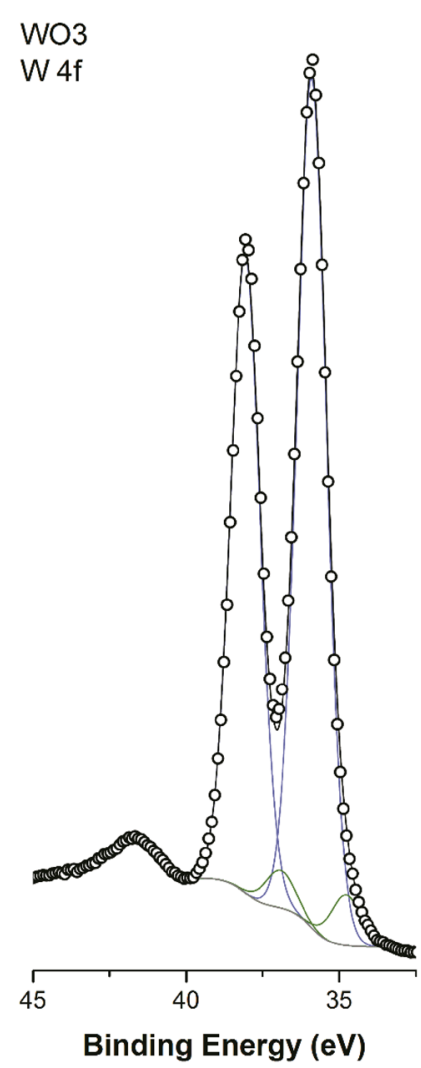

Binding Energy (eV)
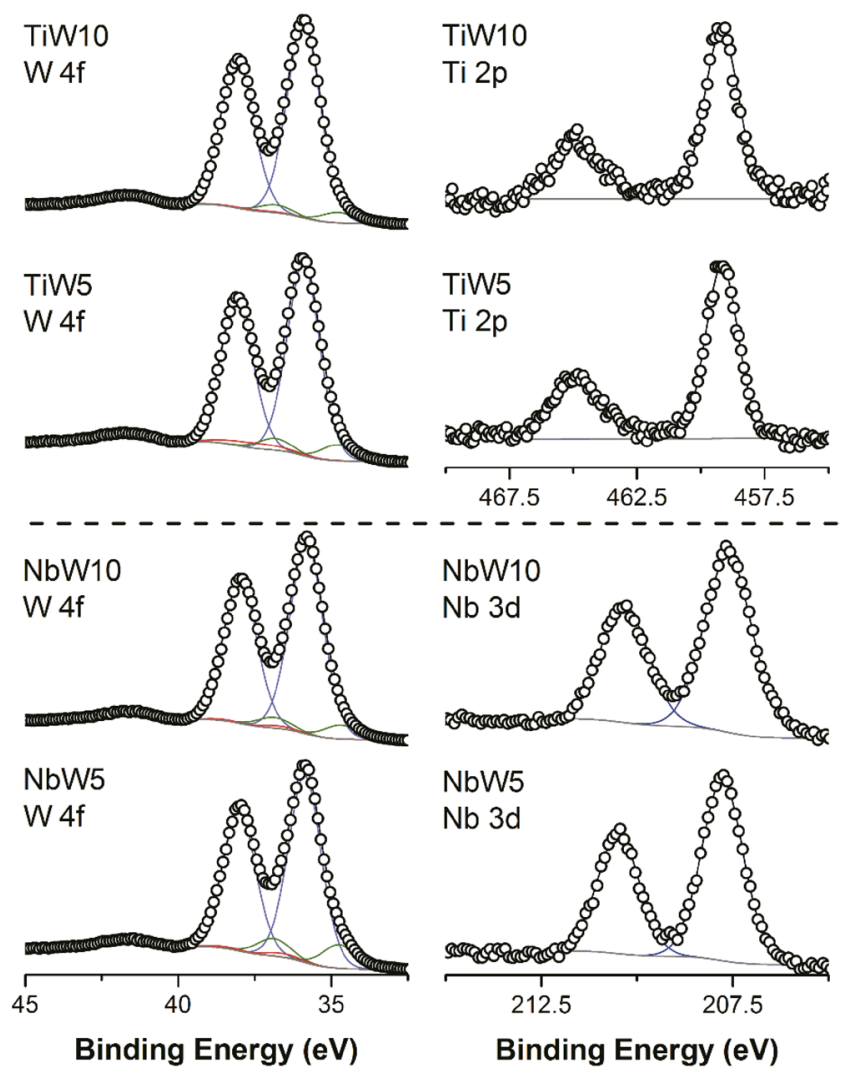

Table 2 Physico-chemical properties of undoped and doped tungsten oxides

\begin{tabular}{llll}
\hline Material & $\begin{array}{l}\mathrm{S}_{\text {BET }} \\
\left(\mathrm{m}^{2} \mathrm{~g}^{-1}\right)\end{array}$ & $\begin{array}{l}\mathrm{N}_{\text {LAS,pyr }} \\
\left(\mathrm{mmol} \mathrm{g}^{-1} / \mu \mathrm{mol} \mathrm{m}{ }^{-2}\right)\end{array}$ & $\begin{array}{l}\mathrm{N}_{\text {BAS,pyr }} \\
\left(\mathrm{mmol} \mathrm{g}^{-1} / \mu \mathrm{mol} \mathrm{m}^{-2}\right)\end{array}$ \\
\hline $\mathrm{WO}_{3}$ & 17 & $0.058 / 3.44$ & $0.029 / 1.70$ \\
NbW10 & 24 & $0.076 / 3.15$ & $0.034 / 1.44$ \\
NbW5 & 35 & $0.099 / 2.84$ & $0.079 / 2.27$ \\
TiW10 & 5.4 & $0.008 / 1.42$ & $0.022 / 4.13$ \\
TiW5 & 3.9 & $0.005 / 1.37$ & $0.039 / 9.91$ \\
\hline
\end{tabular}

found in the diffractograms, showing full incorporation of the dopants into the $\mathrm{WO}_{3}$ framework. This was additionally confirmed by aid of STEM-EDX. Although minor inhomogeneities were observed, no segregation between dopant oxides and tungstite could be detected (Fig. 5).

Previous work shows that doping $\mathrm{WO}_{3}$ with niobium increased the Brønsted acidity of the material [33]. The exchange of Lewis acidic $\mathrm{W}^{\mathrm{VI}}$ cations by $\mathrm{Nb}^{\mathrm{V}}$ species induces a charge defect which is compensated by acidic protons, thus increasing the amount of Brønsted acid sites (BAS). Concurrently, this exchange decreased the number of Lewis acid sites (LAS) as the relative amount of $\mathrm{W}^{\mathrm{VI}}$ is lowered.

The as-produced materials were therefore analyzed on acidic properties using pyridine as probe molecule using

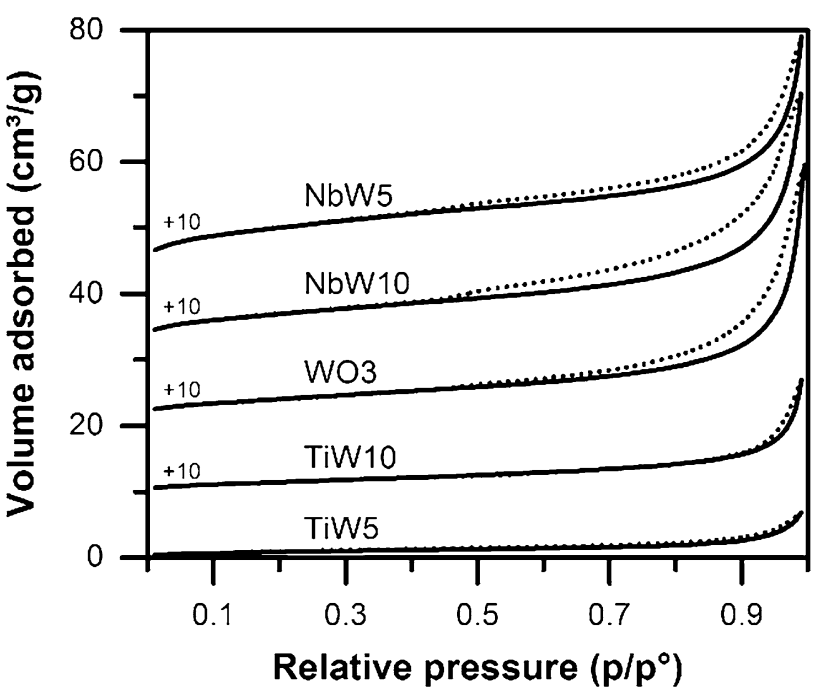

Fig. $2 \mathrm{~N}_{2}$ sorption isotherms of as-prepared materials

integrated molecular absorption coefficients as established by Datka et al. [41] Results are presented in Table 2. Expectedly, undoped $\mathrm{WO}_{3}$ has the highest density of LAS, but also possesses a reasonable density of BAS. The latter are likely derived from the partial reduction of $\mathrm{W}^{\mathrm{VI}}$ to $\mathrm{W}^{\mathrm{V}}$. Generally, increasing amounts of either dopant lowers the amount of LAS and increases the amount of BAS. Additionally, the effects of Ti doping are more pronounced than inclusion of 

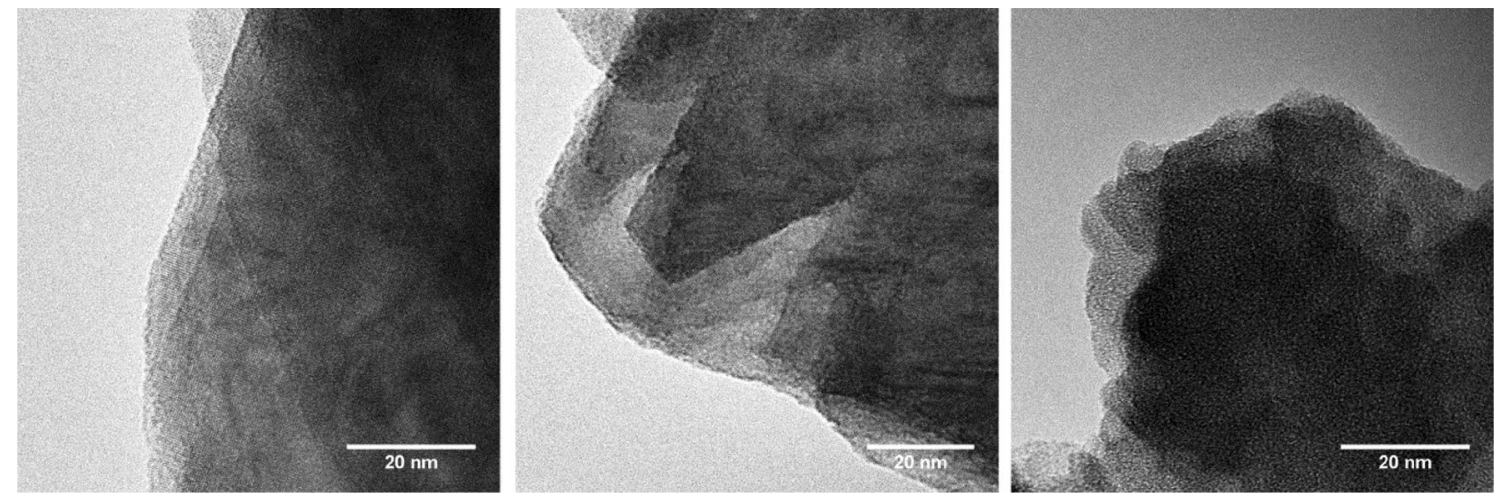

Fig. 3 Representative TEM images of $\mathrm{WO}_{3}$, NbW5 and TiW5

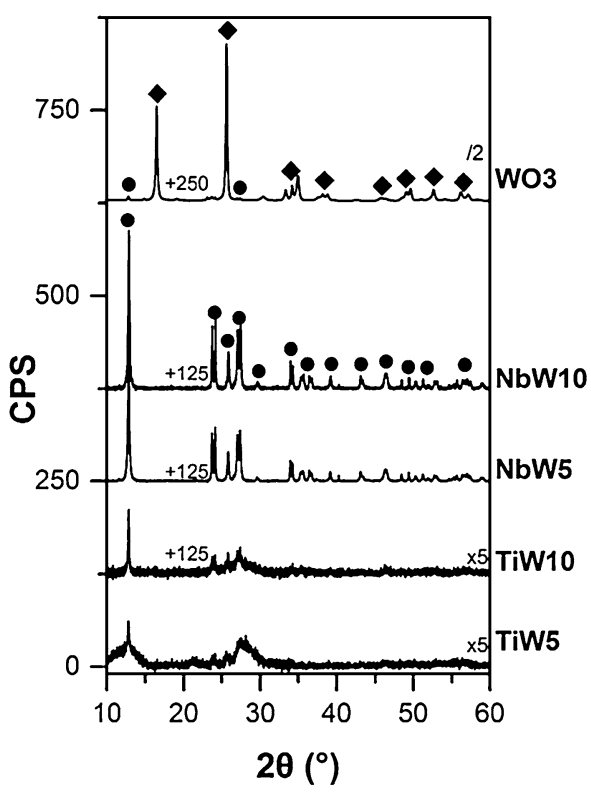

Fig. 4 X-ray diffractograms of the different materials: tungstite is represented by diamond, hydrotungstite by circle

$\mathrm{Nb}$. Where NbW10 presents only a minor decrease in LAS and actually a lower density of BAS, TiW10 loses roughly half of its LAS and possesses more than double the amount of BAS compared to undoped $\mathrm{WO}_{3}$. This trend continues in TiW5 where the density of LAS is reduced slightly and the BAS density is double that of TiW10. We expect that the inclusion of $\mathrm{Ti}^{4+}$ induces a larger charge defect as compared to that $\mathrm{Nb}^{5+}$, which in the extreme case needs compensation by two acidic protons instead of one.

Activity tests of the five materials are displayed in Fig. 6. All materials were able to reach full glucose conversion within $4 \mathrm{~h}$. The conversion rate was substantially higher for the doped materials. Undoped $\mathrm{WO}_{3}$ exhibits a poor selectivity to $\mathrm{HMF}$, evidenced by the low yield of $15 \%$ after $4 \mathrm{~h}$ of reaction (Fig. 6 , left graph). Addition of $\mathrm{HCl}$ after $3 \mathrm{~h}$ increased the yield to
$55 \%$, indicating that the Brønsted acidity of the undoped oxide is too low to efficiently perform the dehydration steps. In contrast, the doped materials were all able to complete this dehydration unaided and with a much higher activity, leading to selectivities of roughly $55-60 \%$. The remainder of the converted glucose is inadvertently lost due to side-product formation such as humins, which can form from glucose, 5-HMF, fructose and other intermediates. Interestingly, the TiWx and $\mathrm{NbWx}$ materials perform equally well, although TiWx has an order of magnitude lower surface area than NbWx. This can be ascribed to the substantially higher density of BAS in TiWx.

As control experiments, the catalytic performance of commercial $\mathrm{Nb}_{2} \mathrm{O}_{5}$ and $\mathrm{TiO}_{2}$ powders was tested using the same conditions as for the undoped and doped $\mathrm{WO}_{3}$ oxides (Fig. 7). Niobia and titania convert glucose relatively fast, as no trace of glucose is found after $30 \mathrm{~min}$ of reaction. Fructose was also not detected at any stage. HMF yields for niobia and titania remain steady after $30 \mathrm{~min}$ at respectively 22 and $0.6 \%$, much lower than any of the tungsten-based oxides. This shows that doped tungsten oxides are a promising material for the promotion of glucose dehydration to 5-HMF.

From the activity data and the literature insights on glucose dehydration mechanism, we can deduce that Lewis acid sites catalyze the initial isomerization step of glucose to fructose $[18,22,32,34,42]$. This leads to fructose as an intermediate. In most experiments, the maximum fructose yield is observed after a reaction time of $30 \mathrm{~min}$. The yield is relatively low in all cases, indicating that fructose is rapidly converted to other products. The remaining steps to obtain 5-HMF from fructose entail dehydration steps, which are catalyzed by Brønsted acid sites.

\section{Conclusions}

Undoped tungsten oxide and niobium- and titanium-doped tungsten oxides were successfully prepared by aqueous precipitation of $\mathrm{WCl}_{6}, \mathrm{NbCl}_{5}$ and $\mathrm{TiCl}_{4}$ with final 


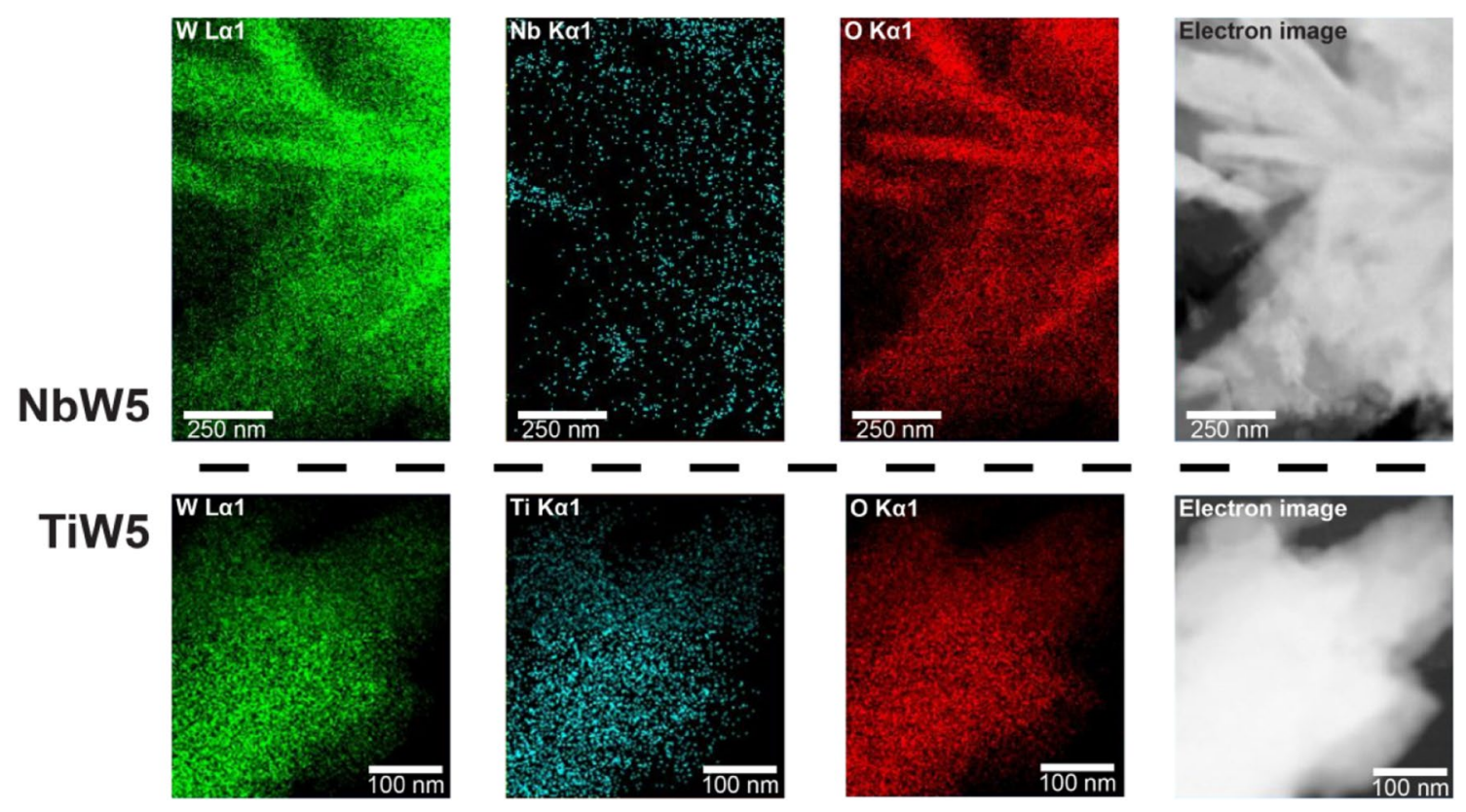

Fig. 5 Elemental EDX maps for NbW5 and TiW5
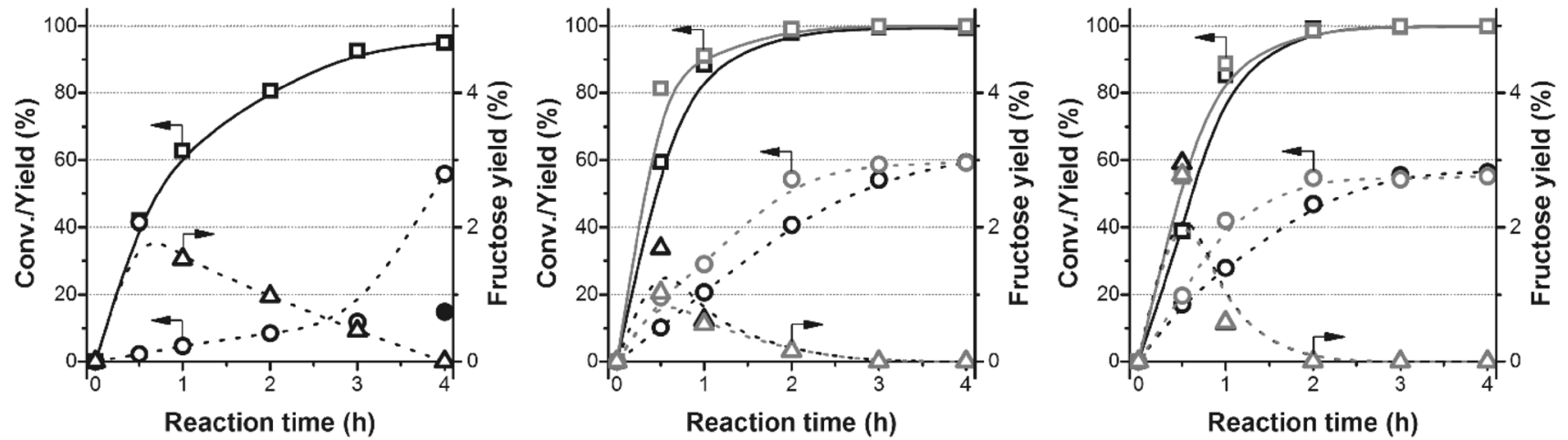

Fig. 6 Activity plots of undoped $\mathrm{WO}_{3}$ (left), $\mathrm{NbWx}$ (center) and TiWx (right). Squares represent glucose conversion, and circles and triangles represent HMF and fructose yield respectively. Closed circle

tungsten/dopant ratios close to desired ratios (5 or 10). The dopants were shown to substantially impact the physicochemical parameters, most notably on surface area and crystal morphology. Niobium improved the surface area, i.e. replacing $20 \%$ of tungsten by niobium led to a two times higher surface area. In contrast, inclusion of $10 \%$ of titanium significantly lowered the surface area. Undoped WO3 comprises a tungstite crystal phase, while doped materials additionally contained a hydrotungstite phase. Separate $\mathrm{Nb}_{2} \mathrm{O}_{5}$ and $\mathrm{TiO}_{2}$ phases were not detected and the dopants were quite homogeneously distributed throughout the materials. Both niobium and titanium led to increased Brønsted acid site densities of the tungstite phase, which for leftmost graph represents $\mathrm{HMF}$ yield when no $\mathrm{HCl}$ is added after $3 \mathrm{~h}$ of reaction time. Gray and black lines in center and right graph represent activity data for $\mathrm{W} /$ dopant $=5$ and 10 respectively

had a positive effect on glucose dehydration, although the final 5-HMF selectivities were mostly unaffected. Optimized 5-HMF selectivities were in the 55-60\% range, the remainder being humins. Interestingly, while both TiW5 and NbW5 have comparable HMF formation rates, their surface areas differ by an order of magnitude. This indicates that TiW5 is significantly more active on a surface area base, which is explained by the relatively high density of Brønsted acid sites. Compared to titania and niobia reference materials that display high glucose conversion rates but low 5-HMF selectivity, doped $\mathrm{WO}_{3}$ stand out as cheap materials with a high density of Lewis and Bronsted acid sites for efficient conversion of glucose to 5-HMF. 


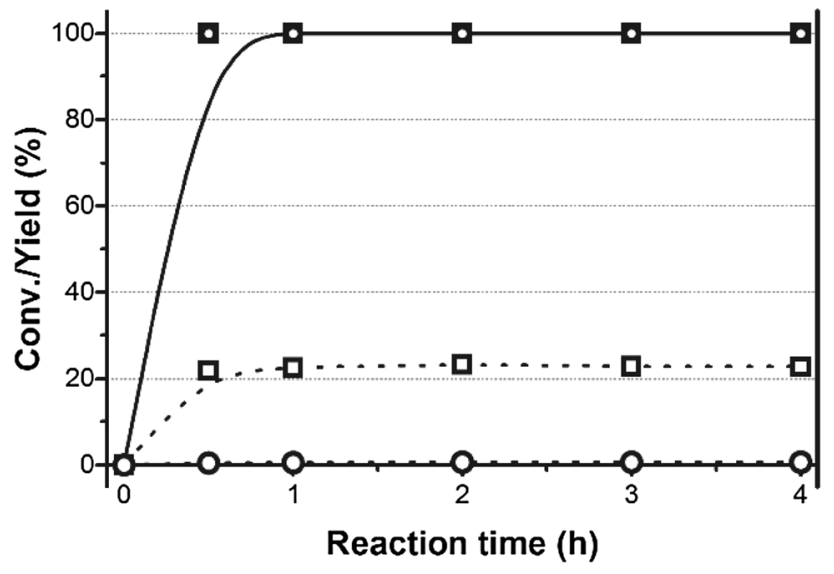

Fig. 7 Activity plots of commercial $\mathrm{Nb}_{2} \mathrm{O}_{5}$ and $\mathrm{TiO}_{2}$. Solid lines represent conversion, dotted lines represent yield. Data for $\mathrm{Nb}_{2} \mathrm{O}_{5}$ is plotted as squares, data for $\mathrm{TiO}_{2}$ as circles. Note that data for conversion overlaps as either oxide reaches $100 \%$ conversion within $30 \mathrm{~min}$

Acknowledgements The authors would like to acknowledge A.M. Elemans-Mehring for assistance with the ICP measurements and M.W.G.M Verhoeven for support with XPS processing. Further thanks are extended to F.D. Tichelaar of NCHREM at Delft University of Techology for performing the STEM-EDX experiments. This work was supported by the Netherlands Center for Multiscale Catalytic Energy Conversion (MCEC), an NWO Gravitation programme funded by the Ministry of Education, Culture and Science of the government of the Netherlands.

\section{Compliance with Ethical Standards}

Conflict of interest The authors declare that they have no conflict of interest.

Open Access This article is distributed under the terms of the Creative Commons Attribution 4.0 International License (http://creativeco mmons.org/licenses/by/4.0/), which permits unrestricted use, distribution, and reproduction in any medium, provided you give appropriate credit to the original author(s) and the source, provide a link to the Creative Commons license, and indicate if changes were made.

\section{References}

1. Corma Canos A, Iborra S, Velty A (2007) Chemical routes for the transformation of biomass into chemicals. Chem Rev 107:2411-2502

2. Kobayashi H, Ohta H, Fukuoka A (2012) Conversion of lignocellulose into renewable chemicals by heterogeneous catalysis. Catal Sci Technol 2:869. https://doi.org/10.1039/c2cy00500j

3. Bozell JJ, Petersen GR (2010) Technology development for the production of biobased products from biorefinery carbohydratesthe US Department of Energy's "Top 10" revisited. Green Chem 12:539. https://doi.org/10.1039/b922014c

4. Gallezot P (2012) Conversion of biomass to selected chemical products. Chem Soc Rev 41:1538-1558. https://doi.org/10.1039/ C1CS15147A
5. Rosatella AA, Simeonov SP, Frade RFM, Afonso CAM (2011) 5-Hydroxymethylfurfural (HMF) as a building block platform: biological properties, synthesis and synthetic applications. Green Chem 13:754. https://doi.org/10.1039/c0gc00401d

6. Van Putten RJ, Van Der Waal JC, De Jong E et al (2013) Hydroxymethylfurfural, a versatile platform chemical made from renewable resources. Chem Rev 113:1499-1597. https://doi.org/10.1021/ cr300182k

7. Qi X, Watanabe M, Aida TM, Smith RL Jr (2009) Efficient process for conversion of fructose to 5-hydroxymethylfurfural with ionic liquids. Green Chem 11:1327. https://doi.org/10.1039/ b905975j

8. Chheda JN, Román-Leshkov Y, Dumesic JA (2007) Production of 5-hydroxymethylfurfural and furfural by dehydration of biomass-derived mono- and poly-saccharides. Green Chem 9:342-350. https://doi.org/10.1039/B611568C

9. Wach W (2004) Fructose. In: Ullmann's encyclopedia of industrial chemistry. Wiley-VCH Verlag GmbH \& Co. KGaA, Weinheim, pp 103-115

10. Meine N, Rinaldi R, Schüth F (2012) Solvent-free catalytic depolymerization of cellulose to water-soluble oligosaccharides. ChemSusChem 5:1449-1454. https://doi.org/10.1002/ cssc. 201100770

11. Rinaldi R, Palkovits R, Schüth F (2008) Depolymerization of cellulose using solid catalysts in ionic liquids. Angew Chem Int Ed 47:8047-8050. https://doi.org/10.1002/anie.200802879

12. Wang J, Xi J, Wang Y (2015) Recent advances in the catalytic production of glucose from lignocellulosic biomass. Green Chem 17:737-751. https://doi.org/10.1039/C4GC02034K

13. vom Stein T, Grande PM, Kayser H et al (2011) From biomass to feedstock: one-step fractionation of lignocellulose components by the selective organic acid-catalyzed depolymerization of hemicellulose in a biphasic system. Green Chem 13:1772. https://doi.org/10.1039/c1gc00002k

14. Nikolla E, Román-Leshkov Y, Moliner M, Davis ME (2011) "One-pot" synthesis of 5-(hydroxymethyl)furfural from carbohydrates using tin-beta zeolite. ACS Catal 1:408-410. https:// doi.org/10.1021/cs2000544

15. Choudhary V, Mushrif SH, Ho C et al (2013) Insights into the interplay of Lewis and Brønsted acid catalysts in glucose and fructose conversion to 5-(hydroxymethyl)furfural and levulinic acid in aqueous media. J Am Chem Soc 135:3997-4006. https ://doi.org/10.1021/ja3122763

16. Zhao H, Holladay JE, Brown H, Zhang ZC (2007) Metal chlorides in ionic liquid solvents convert sugars to 5-hydroxymethylfurfural. Science 316:1597-1600. https://doi.org/10.1126/scien ce. 1141199

17. Girisuta B, Janssen LPBM, Heeres HJ (2006) Green chemicals. Chem Eng Res Des 84:339-349. https://doi.org/10.1205/cherd 05038

18. Garcés D, Díaz E, Ordóñez S (2017) Aqueous phase conversion of hexoses into 5-hydroxymethylfurfural and levulinic acid in the presence of hydrochloric acid: mechanism and kinetics. Ind Eng Chem Res 56:5221-5230. https://doi.org/10.1021/acs. iecr.7b00952

19. Rasrendra CB, Windt M, Wang Y et al (2013) Experimental studies on the pyrolysis of humins from the acid-catalysed dehydration of C6-sugars. J Anal Appl Pyrolysis 104:299-307. https ://doi.org/10.1016/j.jaap.2013.07.003

20. Moliner M, Román-Leshkov Y, Davis ME (2010) Tin-containing zeolites are highly active catalysts for the isomerization of glucose in water. Proc Natl Acad Sci USA 107:6164-6168. https ://doi.org/10.1073/pnas.1002358107

21. Pidko EA, Degirmenci V, Van Santen RA, Hensen EJM (2010) Glucose activation by transient $\mathrm{Cr}^{2+}$ dimers. Angew Chem Int Ed 49:2530-2534. https://doi.org/10.1002/anie.201000250 
22. Yang G, Pidko EA, Hensen EJM (2012) Mechanism of Bronsted acid-catalyzed conversion of carbohydrates. J Catal 295:122132. https://doi.org/10.1016/j.jcat.2012.08.002

23. Yang G, Pidko EA, Hensen EJM (2013) The mechanism of glucose isomerization to fructose over Sn-BEA zeolite: a periodic density functional theory study. ChemSusChem 6:1688-1696. https://doi.org/10.1002/cssc.201300342

24. Zhang Y, Pidko EA, Hensen EJM (2011) Molecular aspects of glucose dehydration by chromium chlorides in ionic liquids. Chem A Eur J 17:5281-5288. https://doi.org/10.1002/chem.201003645

25. Zhao Q, Wang L, Zhao S et al (2011) High selective production of 5-hydroxymethylfurfural from fructose by a solid heteropolyacid catalyst. Fuel 90:2289-2293. https://doi.org/10.1016/j. fuel.2011.02.022

26. Corma A, Nemeth LT, Renz M, Valencia S (2001) Sn-zeolite beta as a heterogeneous chemoselective catalyst for Baeyer-Villiger oxidations. Nature 412:423-425. https://doi.org/10.1038/35086 546

27. Zapata PA, Huang Y, Gonzalez-Borja MA, Resasco DE (2013) Silylated hydrophobic zeolites with enhanced tolerance to hot liquid water. J Catal 308:82-97. https://doi.org/10.1016/j. jcat.2013.05.024

28. Ravenelle RM, Schübler F, Damico A et al (2010) Stability of zeolites in hot liquid water. J Phys Chem C 114:19582-19595. https://doi.org/10.1021/jp104639e

29. Eminov S, Brandt A, Wilton-Ely JDET, Hallett JP (2016) The highly selective and near-quantitative conversion of glucose to 5-hydroxymethylfurfural using ionic liquids. PLoS ONE 11:1-15. https://doi.org/10.1371/journal.pone.0163835

30. Wang H, Liu S, Zhao Y et al (2016) Molecular origin for the difficulty in separation of 5-hydroxymethylfurfural from imidazolium based ionic liquids. ACS Sustain Chem Eng 4:6712-6721. https ://doi.org/10.1021/acssuschemeng.6b01652

31. Noma R, Nakajima K, Kamata K et al (2015) Formation of 5-(hydroxymethyl)furfural by stepwise dehydration over $\mathrm{TiO}_{2}$ with water-tolerant Lewis acid sites. J Phys Chem C 119:1711717125. https://doi.org/10.1021/acs.jpcc.5b03290

32. Nakajima $\mathrm{K}$, Baba $\mathrm{Y}$, Noma $\mathrm{R}$ et al (2011) $\mathrm{Nb}_{2} \mathrm{O}_{5} \cdot \mathrm{nH}_{2} \mathrm{O}$ as a heterogeneous catalyst with water-tolerant lewis acid sites. J Am Chem Soc 133:4224-4227. https://doi.org/10.1021/ja110482r
33. Yue C, Li G, Pidko EA et al (2016) Dehydration of glucose to 5-hydroxymethylfurfural using $\mathrm{Nb}$-doped tungstite. ChemSusChem. https://doi.org/10.1002/cssc.201600649

34. Li G, Pidko EA, Hensen EJM (2016) A periodic DFT study of glucose to fructose isomerization on tungstite $\left(\mathrm{WO}_{3} \cdot \mathrm{H}_{2} \mathrm{O}\right)$ : influence of group IV-VI dopants and cooperativity with hydroxyl groups. ACS Catal 6:4162-4169. https://doi.org/10.1021/acscatal.6b008 69

35. Vasilopoulou M, Palilis LC, Georgiadou DG et al (2011) Reduction of tungsten oxide: a path towards dual functionality utilization for efficient anode and cathode interfacial layers in organic light-emitting diodes. Adv Funct Mater 21:1489-1497. https:// doi.org/10.1002/adfm.201002171

36. Dash JK, Chen L, Topka MR et al (2015) A simple growth method for $\mathrm{Nb}_{2} \mathrm{O}_{5}$ films and their optical properties. RSC Adv 5:36129_ 36139. https://doi.org/10.1039/C5RA05074J

37. Krishnan P, Liu M, Itty PA et al (2017) Characterization of photocatalytic $\mathrm{TiO}_{2}$ powder under varied environments using near ambient pressure X-ray photoelectron spectroscopy. Sci Rep 7:43298. https://doi.org/10.1038/srep43298

38. Yue C, Zhu X, Rigutto M, Hensen E (2015) Acid catalytic properties of reduced tungsten and niobium-tungsten oxides. Appl Catal B 163:370-381. https://doi.org/10.1016/j.apcatb.2014.08.008

39. Bathe SR, Patil PS (2007) Influence of Nb doping on the electrochromic properties of $\mathrm{WO}_{3}$ films. J Phys D 40:7423-7431. https ://doi.org/10.1088/0022-3727/40/23/025

40. Alexander V, Naumkin AKraut-Vass, Stephen W. Gaarenstroom CJP (2017) NIST X-ray Photoelectron Spectroscopy Database, NIST Standard Reference Database 20, Version 4.1. http://srdat a.nist.gov/xps/Default.aspx. Accessed 20 Dec 2017

41. Datka J, Turek AM, Jehng JM, Wachs IE (1992) Acidic properties of supported niobium oxide catalysts: an infrared spectroscopy investigation. J Catal 135:186-199. https://doi.org/10.1016/00219517(92)90279-Q

42. Saha B, Abu-Omar MM (2014) Advances in 5-hydroxymethylfurfural production from biomass in biphasic solvents. Green Chem 16:24-38. https://doi.org/10.1039/C3GC41324A 